\author{
M. Korzeniowski ${ }^{1 *}$, T. Piwowarczyk ${ }^{1}$, P. Kustroń ${ }^{1}$, A. Czubak ${ }^{2}$ \\ ${ }^{1}$ Wroclaw University of Technology, Faculty of Mechanical Engineering, \\ Lukasiewicza 5, 50-371 Wroclaw, Poland, marcin.korzeniowski@pwr.wroc.pl \\ ${ }^{2}$ HSETeam S. C.
}

\title{
LOW-ENERGY WELDING METHODS USED FOR SEMI-AUTOMATIC THIN-WALLED AUTOMOTIVE STEELS
}

\begin{abstract}
The paper deals with the issues of welding modern car-body steels (including dual phase (DP), high strength low alloy (HSLA) and deep-drawing (DC) grades) using low-energy methods. In view of small thickness of elements to be joined, welding them with conventional arc methods has becoming more and more rare and has been replaced with methods which, while ensuring required strength properties of joints, deliver substantially less heat to the weld, thus limiting its effect on the structure being welded. Examinations (visual inspections, strength tests, hardness measurements) allowed an objective evaluation of selected low-energy methods with respect to MAG welding with $\mathrm{CO} 2$ shielding.
\end{abstract}

Key words: semi-automatic low energy welding, automotive steels, strength testing od welding joints

\section{INTRODUCTION}

Development of contemporary's new welding technologies tends to reducing energy consumption and increasing the quality and strength of joining elements. In automotive industry arc welding is one of the most common method of joining. Evolving variety of materials, pursuing to mass redaction by using thinner metal plates and joining two different materials cause that the welding process have to develop to be equal to high requirements automotive industry.

Beside car production welding technique is also used for repairing, especially motor-car body or chassis. Those parts of vehicles are often made of different materials and commonly used for years MIG/MAG welding may be inapplicable. In automotive industry thickness of elements to be welded rarely exceed $2.5 \mathrm{~mm}$. In case of thinner parts (up to $1.5 \mathrm{~mm}$ ) to much heat delivered into the joint may cause undercuts of the edges of welded sheets. Decreasing of the welding current has no effect, because of short arc, a lot of scatters appears causing welding process unstable. The needs for arc welding of thin sheets forced the welding equipment manufacturers to develop methods which allow to get proper joints using as low welding current with the stable arc. The low energy welding processes seems to be one of the most perspective methods of joining thin elements in automotive industry $[1,2,3]$. 
Over several years on welding market few new arc welding methods appeared: limitation of heat by welding current modulation known as pulse arc [4,5], and more sophisticated: EWM's ColdlArc and Fronius's CMT (Cold Metal Transfer) [2,6,7].

\section{CHARACTERIZATION OF STEEL USED IN THE RESEARCH}

Examinations were made for modern car-body steels of the greatest share in automotive market: DP800 dual phase, HSLA420 micro-alloyed higher strength and DC04 deep-drawing grades.

\section{Dual-phase steel}

DP steel is from advance high strength steel group. The structure of this steel is based on grained polygonal or acicular ferrite (ductile phase) with hard martensite phase in the form of island, in amount of $5-40 \%$, sometimes small amount of retained austenite can occur. Increasing of martensite phase leads to an increase of strength.

The simples way to obtain a dual-phase steel in controlled cooling after annealing in rage of temperature suitable for the $\alpha+\gamma$ two-phase field. During quenching takes place the austenite to martensite transformation which gives dual-phase structure (ferrite+martensite).

The second method to achieve a dual-phase steel bases on thermo-mechanical treatment, which consists in integration of heat treatment with plastic forming in the other words it is hot-rolling with progressive cooling. This treatment gives more close-grained structure what provide better mechanical properties.

Dual-phase steel presents a number of excellent properties which, depend on the ratio of its two phases and on the size of grains. This steel demonstrate continuous yield behavior, low $0.2 \%$ offset yield strength, high work hardening rate, high tensile strength, even higher than $1000 \mathrm{MPa}$, and remarkable high uniform and tensile elongation[8,9,10].

\section{High-strength low-alloy steel}

HSLA belongs group of high strength steel designed to promote excellent high yield characteristics and is for cold working. Without additional heat treatment has better mechanical properties and greater resistance to corrosion then carbon steels. This type of steel in the hot rolled condition has ferritic-pearlitic microstructure with vary small amount of carbon alloys max. $0.2 \% \mathrm{C}$, Mn up to $1.8 \%$ and other microadditives like Al- $0.02 \%$, V$0.15 \%, \mathrm{Nb}-0.05 \%$, and more or less $0.025 \%$ of $\mathrm{N}$. This microadditives create with $\mathrm{C}$ and $\mathrm{N}$ stable carbides and nitrides which precipitate during rolling on grain boundaries and other lattice defects. Addition of niobium, titanium, copper and vanadium improves strengthening and are intended for modification of the microstructure of carbon steel (ferrite-pearlite aggregate) to creates very fine dispersion of alloys carbides in an almost pure ferrite matrix, what is eliminating toughness by reducing effect of a pearlitic fraction. The yield strength of HSLA can be between 250-590 MPa, in comparison to unalloyed, low-carbon steels (witch identical $\mathrm{C}$ content), these steels demonstrate almost twice as high yield point and tensile strength. For improving HSLA's corrosion resistance are added copper, silicon, nickel, chromium and phosphorus, while zirconium, calcium, and rare earth elements are added for sulphide-inclusion shape control which increases formability. 
HSLA steel is used in structures which are designed to handle large amount of stress or needs a good strength-to-weight ratio, so is perfect for production of car, trucks, cranes, bridges or roller coasters [8].

\section{Deep drawing steel}

Deep drawing steel can have pure ferrite structure or ferrite matrix which can contain isolated grainy carbides. Provides good resistance to aging and its yield strength range from 140 to $250 \mathrm{MPa}$. Due to its excellent formability deep drawing steel guarantee minimum performance as regards crash behavior and fatigue strength and demonstrate the lower limit with regard to loadability. Deep drawing steel may be present in two form as a hot-rolled deep drawing steel and as a cold rolled deep drawing steel. Thanks to targeted surface structure and perfect formability of cold rolled deep drawing steels can be intended for production of complex body outer, inner panels, fenders side panel frames, floor panels, spare wheel wells or door outer and inner panels. Whereas the hot-rolled grade can be used for production of body and structure parts, chassis parts, and wheel rims [11].

Chemical composition and basic mechanical properties of DP800, HSLA340 and deep drawing DC04 steel have been presented in tables 1 and 2.

Table 1. Chemical composition of steels used in research

\begin{tabular}{|l|c|c|c|c|c|c|c|c|c|c|c|}
\hline \multirow{3}{*}{ Steel } & \multicolumn{10}{|c|}{ Chemical composition in \% weight } \\
\cline { 2 - 13 } & $\mathrm{C}$ & $\mathrm{Si}$ & $\mathrm{Mn}$ & $\mathrm{P}$ & $\mathrm{S}$ & $\mathrm{Al}$ & $\mathrm{Cr}$ & $\mathrm{Ni}$ & $\mathrm{V}$ & $\mathrm{Ti}$ & $\mathrm{Nb}$ \\
\hline DP 800 & 0,12 & 0,19 & 1,50 & 0,013 & 0,005 & 0,045 & 0,04 & 0,04 & 0,01 & 0 & 0 \\
\hline HSLA 320 & 0,05 & 0,011 & 0,727 & 0,012 & 0,006 & 0,036 & 0 & 0 & 0,001 & 0,001 & 0,048 \\
\hline DC04 & 0,05 & 0,02 & 0,26 & 0,012 & 0,011 & 0,052 & 0,02 & 0,02 & 0 & 0 & 0 \\
\hline
\end{tabular}

Table 2. Mechanical properties of steels used in research

\begin{tabular}{|l|c|c|c|}
\hline \multirow{2}{*}{} & \multicolumn{3}{|c|}{ Mechanical properties } \\
\cline { 2 - 4 } & $\mathrm{R}_{\mathrm{p} 0.2}[\mathrm{MPa}]$ & $\mathrm{R}_{\mathrm{m}}[\mathrm{MPa}]$ & $\mathrm{A}_{80}[\%]$ \\
\hline DP800 & $500-640$ & $800-950$ & 12 \\
\hline HSLA340 & $320-400$ & 480 & 22 \\
\hline DC04 & 210 & $270-350$ & 38 \\
\hline
\end{tabular}

\section{METAL TRANSFER MECHANISM}

Significant influence on welding process has metal transfer mechanism, which can be divided on three basic methods of metal transferring from the electrode to the workspace: short-circuiting transfer, globular transfer and spray transfer. On metal transfer mechanism the most influential are welding parameters such as: current intensity, arc voltage, shielding gas composition and the method of wire feeding. 


\section{Short-circuiting transfer in MAG welding}

The American Welding Society defines short circuiting transfer as metal transfer in which molten metal from consumable electrode is deposited during repeated short circuits [12]. It means that the short-circuiting transfer appears when the electrode is in contact with the weld pool what results in short circuit and the electric arc is burning. In this case is no free metal transfer across the arc. The electrode contacts the molten weld pool with constant frequency from 20 to 200 times per second, depending on the current parameters setting, device inductance, type of shielding gas, material and electrode diameter.

Figure 1 shows one complete short arc cycle. At the time when the electrode is touching the weld pool, what causes the short circuit in the welding circuit, the arc starts burning. During short circuit in welding circuit current increases. The intensity of current should be high enough to heat and melt the electrode and eventually initiate the metal transfer. However must be low enough to minimize spatter. The spatter is caused by violent separation the metal drop. At the same time the open circuit voltage of the power source must to be low enough so that the molten metal drop will not separate from electrode until it contact the molten pool. At the same time the current begins to rise the wire starts to deform or neck down because of electromagnetic pinch effect. Electromagnetic pinch effect controls the separation of molten metal's drops from the electrode wire and it it the most important factor which controls metal transfer. After separation of metal drop from the electrode the drop is dissolving in the welding pool and the arc starts to free burn brightly.

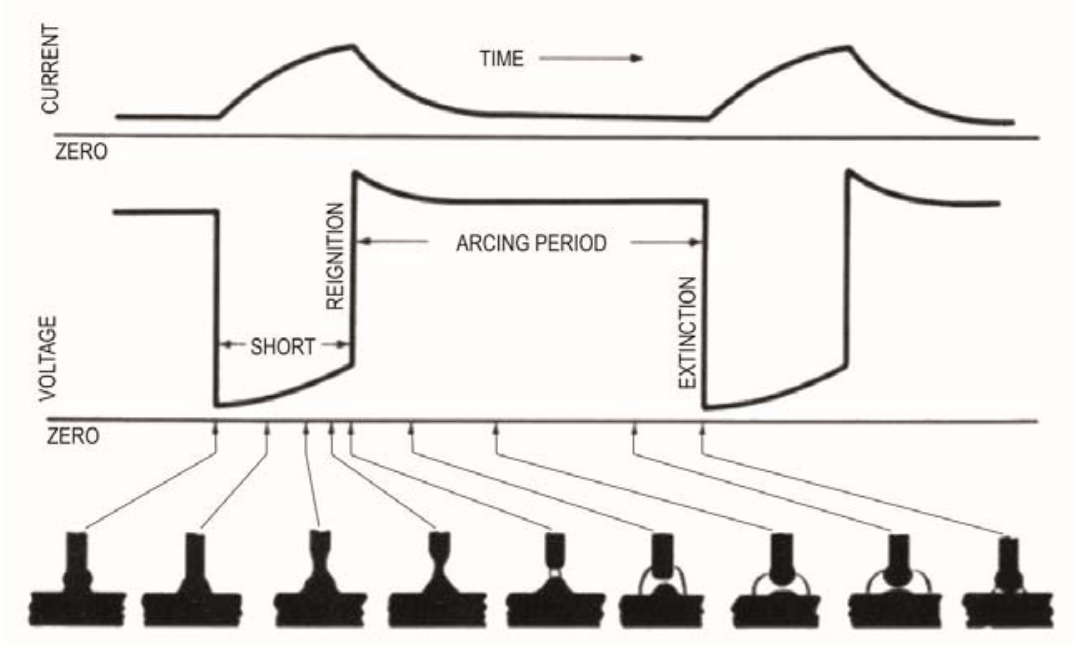

Fig. 1. Mechanism of short circuiting [13]

\section{Metal transfer in ColdArc welding}

ColdArc is a short arc process with cyclical changes between phases of the arc and short circuit. The idea of EWM's ColdArc process is strict and precise control of electric power delivered to the welding area.

Figure 2 shows the differences in voltage outline between MAG and Cold Arc process, and as we can see during phases of the arc, short circuit and in time of arc re-ignition the 
voltage outline of the ColdArc process is the same like in the MAG process and after arc reignition we can observe sudden decreasing of voltage. The outer power is used as an indicator while controlling the current. The reaction to all changes has to be taken immediately and has to be dynamic that why the measurements of current have to be constant, if welding thin sheet process has to finish successfully. To specify the power of arc just before re-ignition in time less than $1 \mathrm{~ms}$ to achieving very gently re-ignition, can be used digital signals processor.

Due to the fact that on the tip of the electrode must be enough amount of molten metal, immediately after re-ignition the current is increasing for very short and define period of time, up to the melt pulse. Only in that moment current decreasing to the basic value, which is extraordinarily low, to minimized further electrode melting. This is the end of the circuit after that new circuit began. Softness and lightness of process provides a melting cone with constant dimension, which is generated by melt pulse after each short circuit [7].

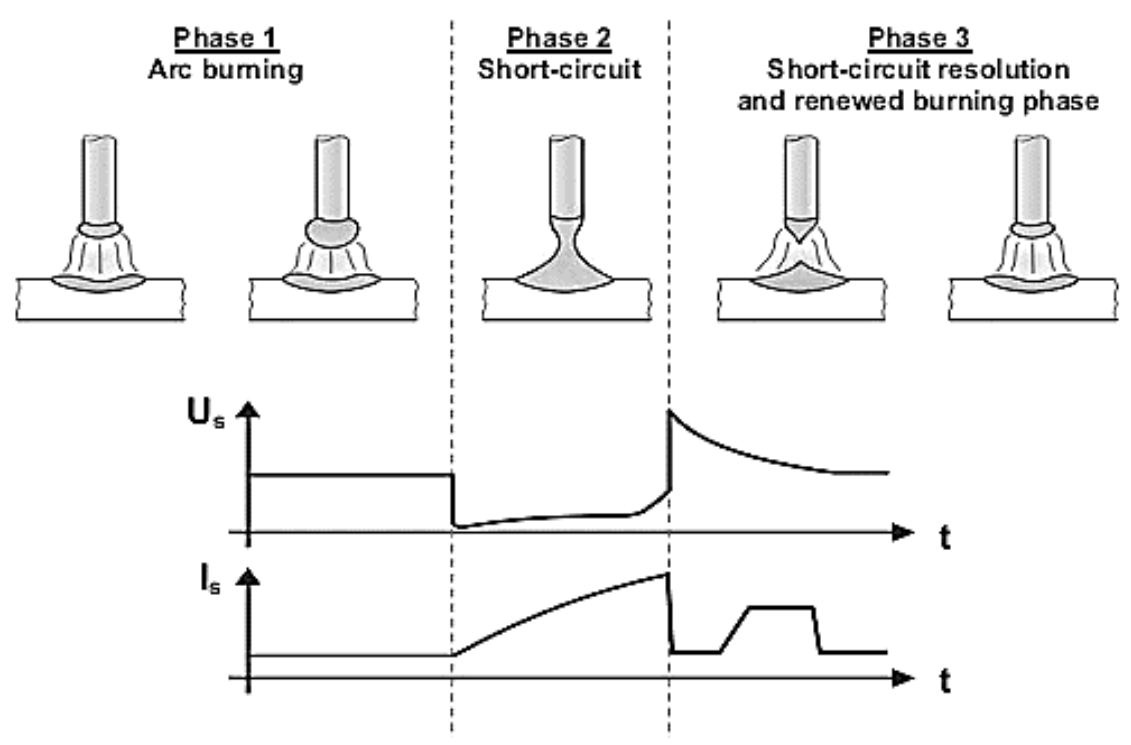

Fig. 2. Metal transfer, current and voltage outline in ColdArc welding process [7]

\section{Cold Metal Transfer (CMT)}

The CMT process begins in the direction of movement of electrode into the weld. At the moment of short circuit, electrode begins to reverse. The end of the wire is detached and molten metal starts moving into the weld pool. From this moment of process the cycle starts again. Very characteristic feature of the transition of metal liquid droplet to the weld is a very low current. Raising the wire causes easier separation the droplets of the liquid metal. This is the reason the short circuit current can be considerably reduced and the heat as well.[1,2]. 


\section{RESULTS OF INVESTIGATION}

The research have been divided for few stages: selection of the materials to be welded and consumables, welding process and its testing: visual, tensile strength, and hardness testing.

The materials used in examinations were the following steels: DP800 dual phase, H340LA high strength micro-alloyed and DC04 deep-drawing grades, all $1 \mathrm{~mm}$ thick. All these grades belong to low-carbon steels and are considered as good weldable (carbon equivalent determined from Ito-Bessyo relationship for steels DP800, HSLA340 and DP04 is $0.21 \%, 0.09 \%$ and $0.07 \%$, respectively).

Welding electrode, type G3Si1 $0.8 \mathrm{~mm}$ thick was used as an additional material. As the shielding gases, $100 \% \mathrm{CO} 2$ was used for classic MAG method and the mixture $\mathrm{Ar}+\mathrm{CO} 2$ in proportion of $82 \%$ Ar and $18 \% \mathrm{CO} 2$ was applied for ColdArc and CMT methods. The shielding gas flow rate was $12 \mathrm{~L} / \mathrm{min}$.

Welding parameters (current intensity, arc voltage and speed) were selected experimentally for ach method in use. The minimum current intensity ensuring stable arc burning and also a full joint penetration of the sheets being welded was regarded as the optimum value. Two butt joints were made for each selected material and for each method used. These joints were then examined. Welding process was carried out manually by a welder with long experience in welded constructions. Welding parameters of a given welding method were the same for each of selected steel grades (Table 3).

Table 3. Set welding parameters

\begin{tabular}{|l|c|c|c|c|}
\hline \multicolumn{1}{|c|}{ Type of steel } & $\begin{array}{c}\text { Current } \\
{[\mathrm{A}]}\end{array}$ & $\begin{array}{c}\text { Voltage } \\
{[\mathrm{V}]}\end{array}$ & $\begin{array}{c}\text { Wire feed } \\
\text { speed } \\
{[\mathrm{cm} / \mathrm{min}]}\end{array}$ & $\begin{array}{c}\text { welding speed } \\
{[\mathrm{cm} / \mathrm{min}]}\end{array}$ \\
\hline MAG & 40 & 15.5 & 250 & 30 \\
\hline ColdArc & 40 & 15.5 & 250 & 30 \\
\hline CMT & 75 & 12 & 300 & 30 \\
\hline
\end{tabular}

\section{Visual testing of joints made of steel HSLA340}

Visual inspections were run according to shaded areas in the standard PN-EN ISO 5817:2009. Figure 3 illustrates the view of welded joints for HSLA340 using the methods: MAG with $100 \% \mathrm{CO}_{2}$ shield, ColdArc and CMT. Visual inspections founded that the most irregular shape of weld face was for classic MAG method (Fig. 3). For this method, it was furthermore observed the largest amounts of oxides generated on weld face surface caused by elements which bonded oxygen created from shielding gas $\left(\mathrm{CO}_{2}\right)$ disintegration. A negative feature of this process is very large amount of welding spatters which prevent from qualifying the weld to any quality class ( $\mathrm{B}$ - stringent, $\mathrm{C}$ - medium, or $\mathrm{D}$ - lenient requirements). 
a)
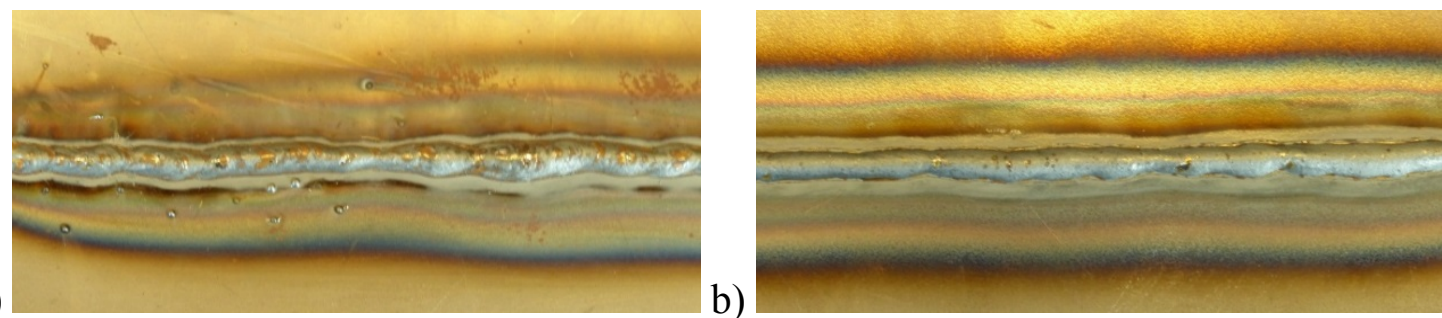

c)

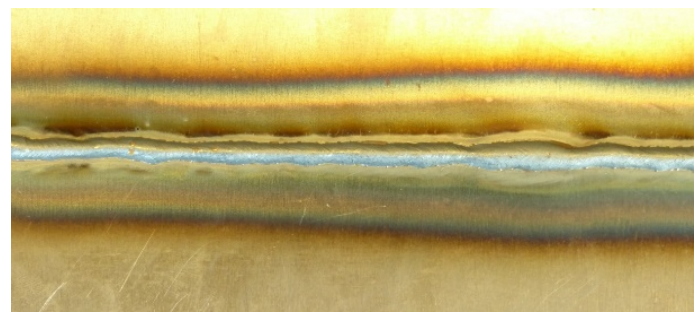

Fig. 3. Samples examined by visual testing

In case of welds made with ColdArc and CMT methods, the weld face is of smooth regular shape and single spatters allow qualifying the joints to the quality class $\mathrm{C}$. Small amounts of oxides on face surface result from other mixture of shielding gases $(82 \% \mathrm{Ar}$ and $18 \% \mathrm{CO} 2$ ) used during welding with low-energy methods. Similar results were found for the remaining joints made for DP800 and DC04 steel grades.

\section{Tensile strength testing}

In order to determine the strength properties, specimens were cut out of the welded joints and then examined for tensile strength in testing machine. The test was carried out according to the norm ISO 4136:2001(E) on standardized flat samples. Total length of specimens was $300 \mathrm{~mm}$, measuring range length was $75 \mathrm{~mm}$ and measuring range width $-12 \mathrm{~mm}$. While specimens subjected to tensile test, applied force was measured. The values of stresses on stress-strain curve were converted according to the force referenced to the initial cross-section area of specimens amounted to $12 \mathrm{~mm}^{2}$. For achieving reliable results from one weld were taken three specimens. The tensile test specimen was mounted in a machine that the both ends of samples were clamped in the jaws of testing machine. One jaws was stationary, the second one was extended the samples with constant speed $(2 \mathrm{~mm} / \mathrm{min})$. The tested specimen was extended until fracture occurred. The highest stress value determines the value of ultimate strength of samples. Obtained results has been presented as stress in a function of elongation.

Figure 4 illustrates tensile test averaging curves for butt joints out of DP800, HSLA340 and DC04 steel grades welded with MAG method and low-energy ColdArc and CMT methods.

Figure 5 shows strength testing results for joints made of specific material with various welding methods. 
a)

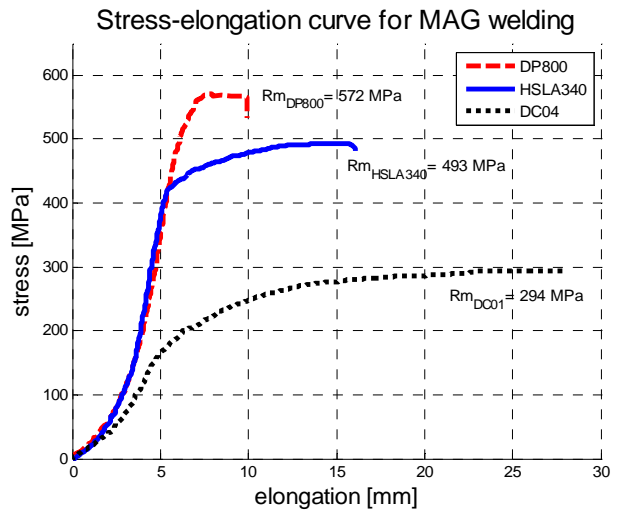

b)
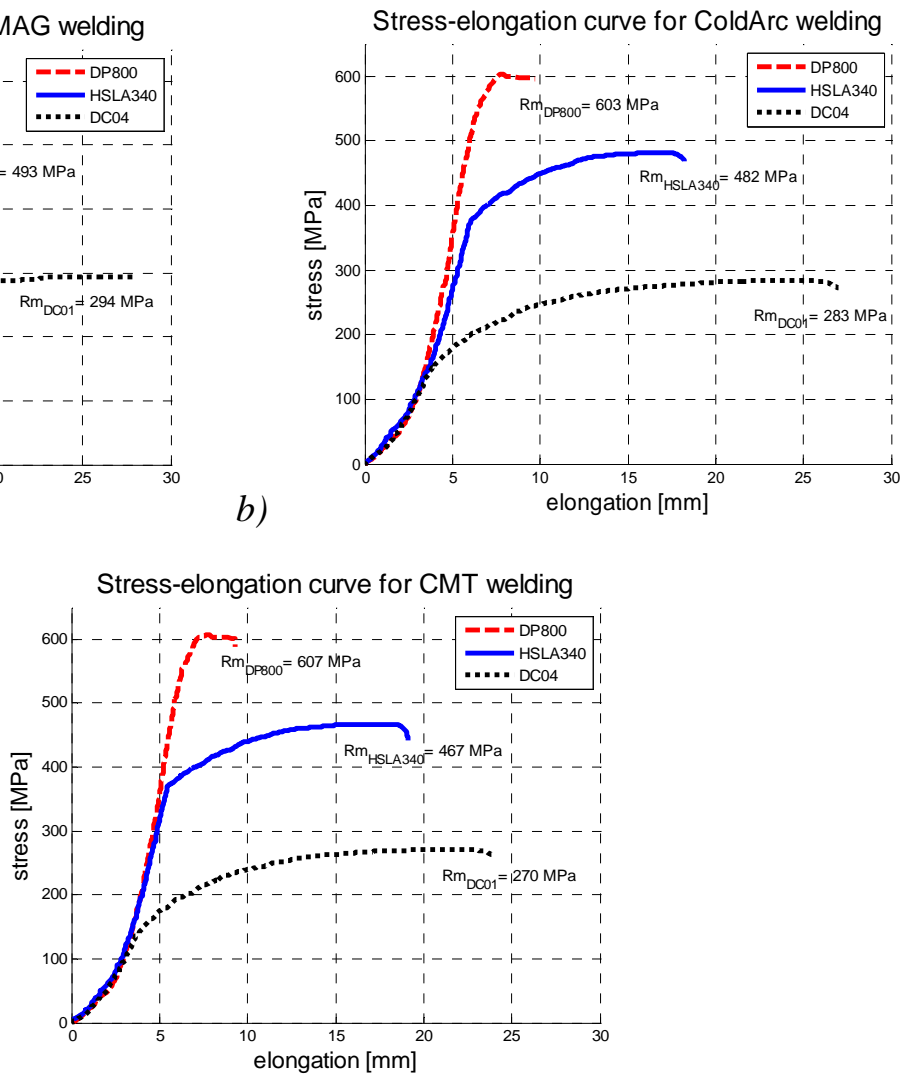

Fig. 4. Comparison of results from tensile test for welded joints made of HSLA, DC04 and DP800 steels by MAG - a) ColdArc -b) and CMT - c) welding processes

a)

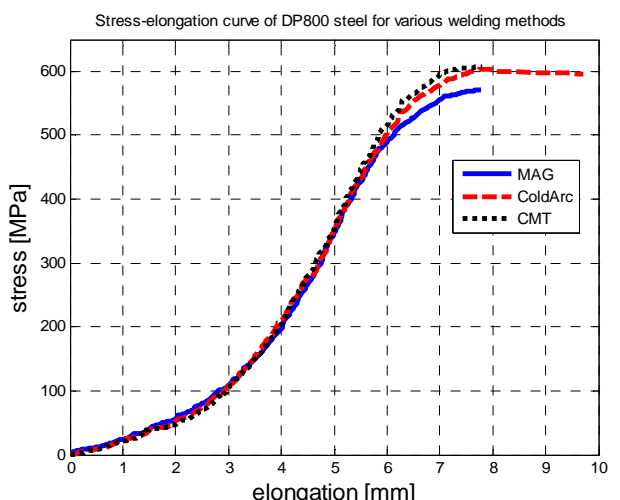

b)

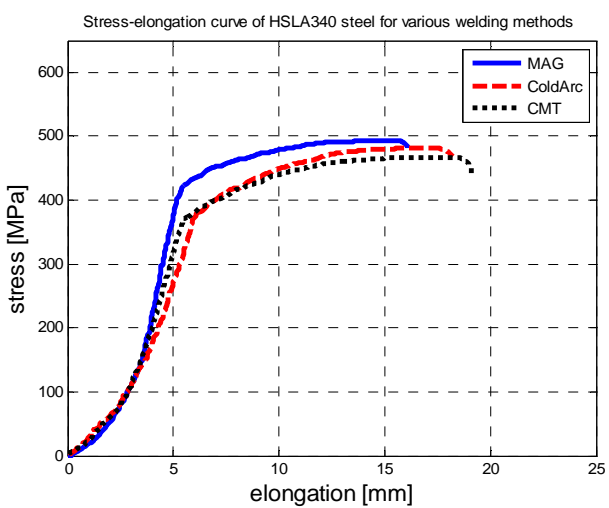

c)

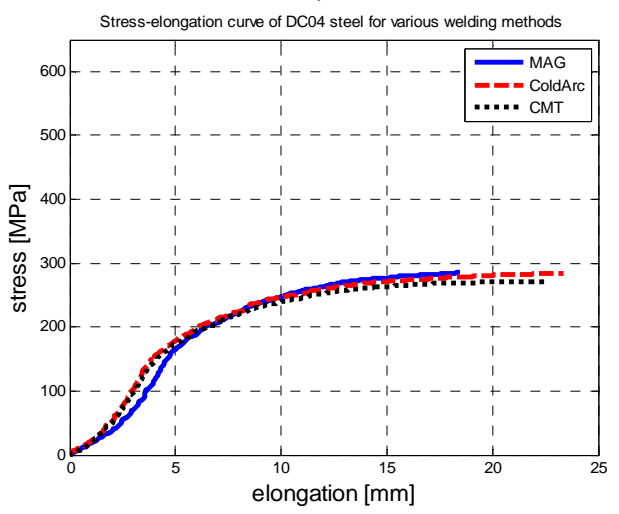

Fig. 5. Comparison indicating effect of welding method (MAG, ColdArc, CMT) on joint strength for steel grades DP800 - a), HSLA340 - b) and DC01 - c) 
Basing on testing carried out, no explicit evaluation can be made about effect of welding method on joint strength. In all tests, the maximum force is conditioned by the parent material strength. Hence, the highest strength was reached by joints of DP800 steel. View of specimens for steel grades DP800, HSLA340 and DC04 is shown in Fig. 6,7,8. In view of no essential differences between two low-energy methods, samples welded with MAG and ColdArc methods are presented.

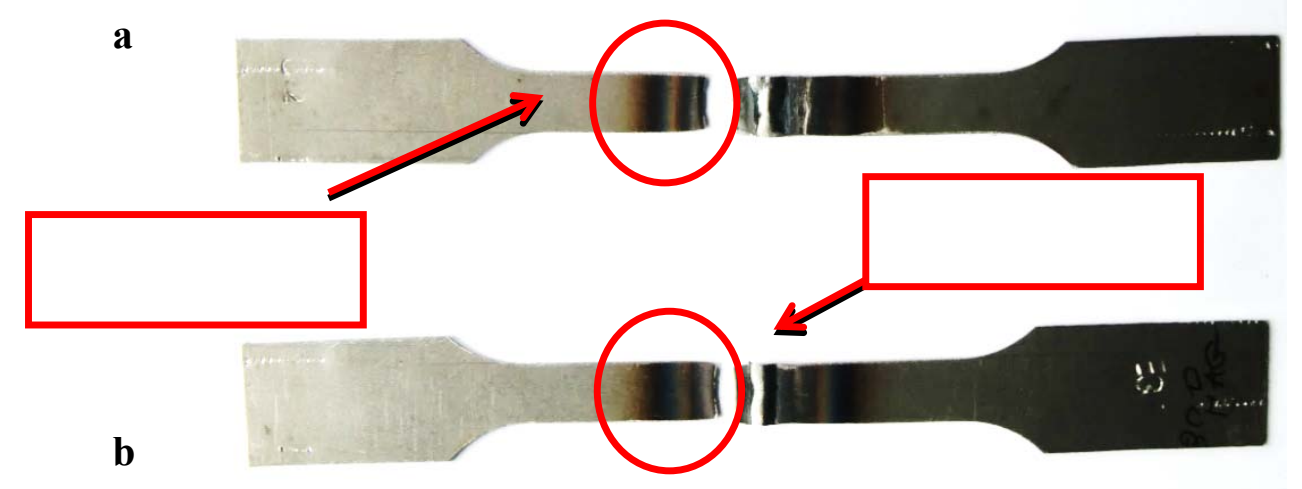

Fig. 6. Examined specimen of DP800 after fracture; a-specimen after ColdArc welding, b- specimen after MAG welding process

a

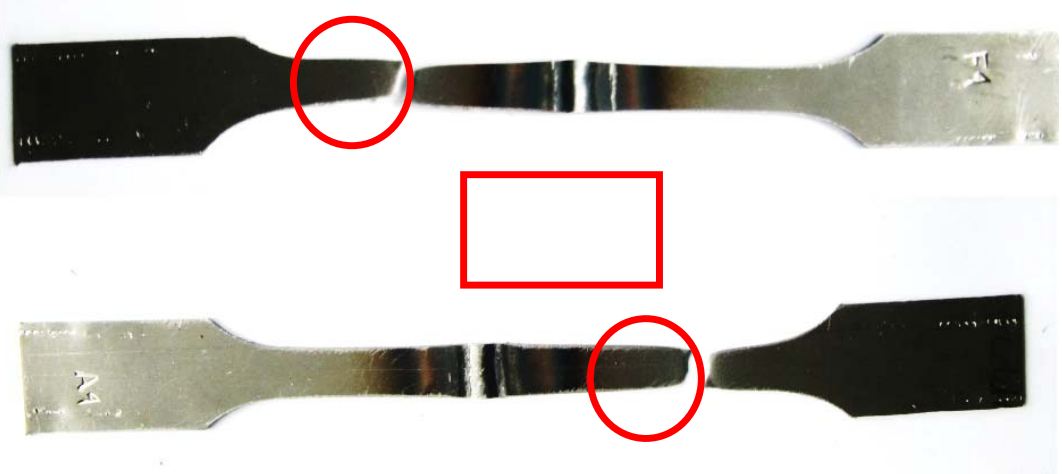

b

Fig. 7. Examined specimen of DCO4 after fracture; a-specimen after MAG welding, b-specimen after ColdArc welding process

$\mathbf{a}$

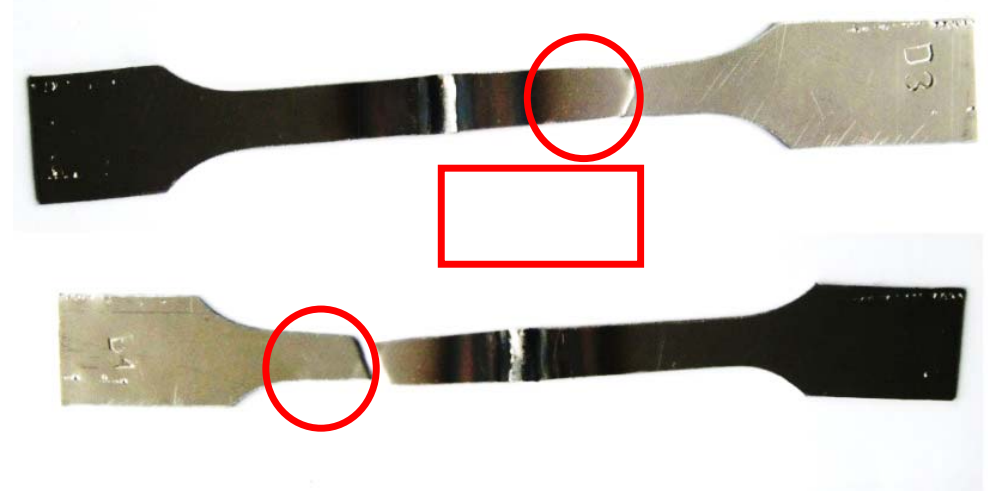

Fig. 8. Examined specimen of HSLA after fracture; a-specimen after MAG welding, b- specimen after ColdArc welding process

The results of shows that the welding method does not has significant influence on strength of welded joints. During examination of HSLA and DC04 steel (fig. 7,8) the obtained values do not shows the strength of welded joint but strength of material- the 
fracture appears out of weld zone. It means that joints have higher strength than base material. Tests of DP800 steel demonstrate that the fracture appears in heat affected zone.(fig. 6a,b). It is worth to draw attention to the nature of failure and to the tensile strength of specimens made out of DP800 steel. Even though these joints feature the highest strength, its value (equalling to about $620 \mathrm{MPa}$ ) is more than $20 \%$ lower than that of the parent metal ( 800 $\mathrm{MPa}$ ). This may results from the content of alloy elements in the steel (mainly the higher content of carbon and manganese) and their effect on structural changes taking place in heataffected zone during welding.

When compared the tensile test with the metallographic samples examination can be seen interesting thing, that is macroscopic examination of butt joint made on DC04 steel (fig. 9c) demonstrates very shallow penetration what should influenced on strength of welded joint but during tensile test the fracture appears not in HAZ but in based material (fig. 7), what means the joint has higher strength.

\section{Macroscopic examinations}

The results of macroscopic examinations were classified according to the standard PNEN ISO 5817:2007, which specifies the required dimensions of the weld for particular quality classes. Specimens of DC04 steel shown in Fig. 9 were selected for testing.
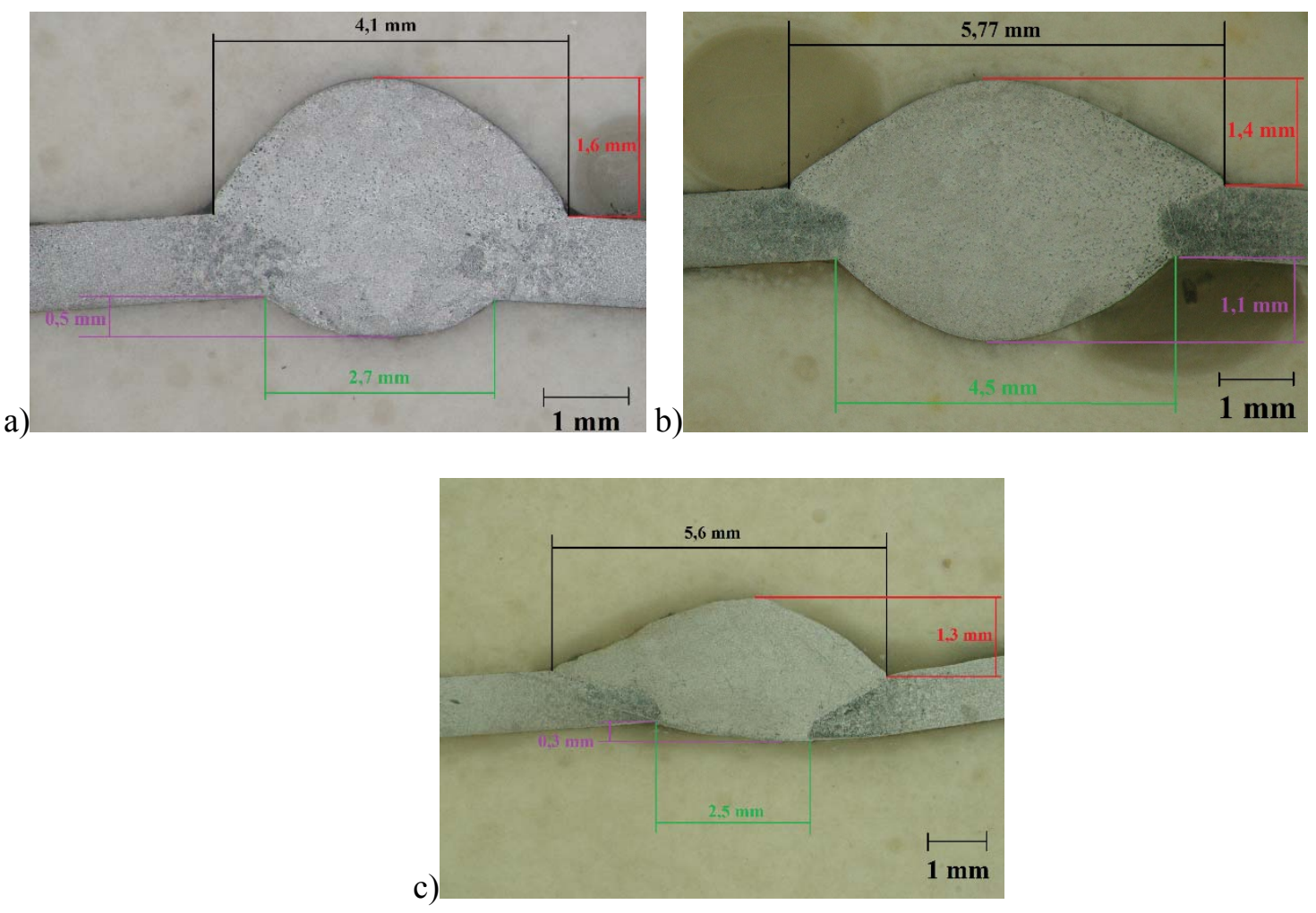

Fig. 9. Macrostructures of DC04 steel butt welds welded with MAG method in CO2 shielding a), welded with ColdArc method b), with CMT method c)

Examinations proved that there are no essential differences in geometrical dimensions of welds made with various methods. The face and root widths are approximately the same for MAG method with $100 \%$ CO2 shielding and Cold Arc method. An essential difference in root height was observed for CMT method in which no excess penetration bead was found. This 
fact is undoubtedly an advantage of this method. A distinct lack of sheet parallelism was observed for all welding methods applied; it can results from stresses affecting the weld which was made in one pass over a distance of $300 \mathrm{~mm}$.

\section{Hardness measurements}

Hardness measurements for joints were run according to the standard ... at the load of 0.5 $\mathrm{kg}$. The measurement was carried out in one direction, from the weld centre towards the sheet in parallel to its surface at points spaced each other by $1.0 \mathrm{~mm}$. A scheme of hardness measurements was shown in Fig. 10.

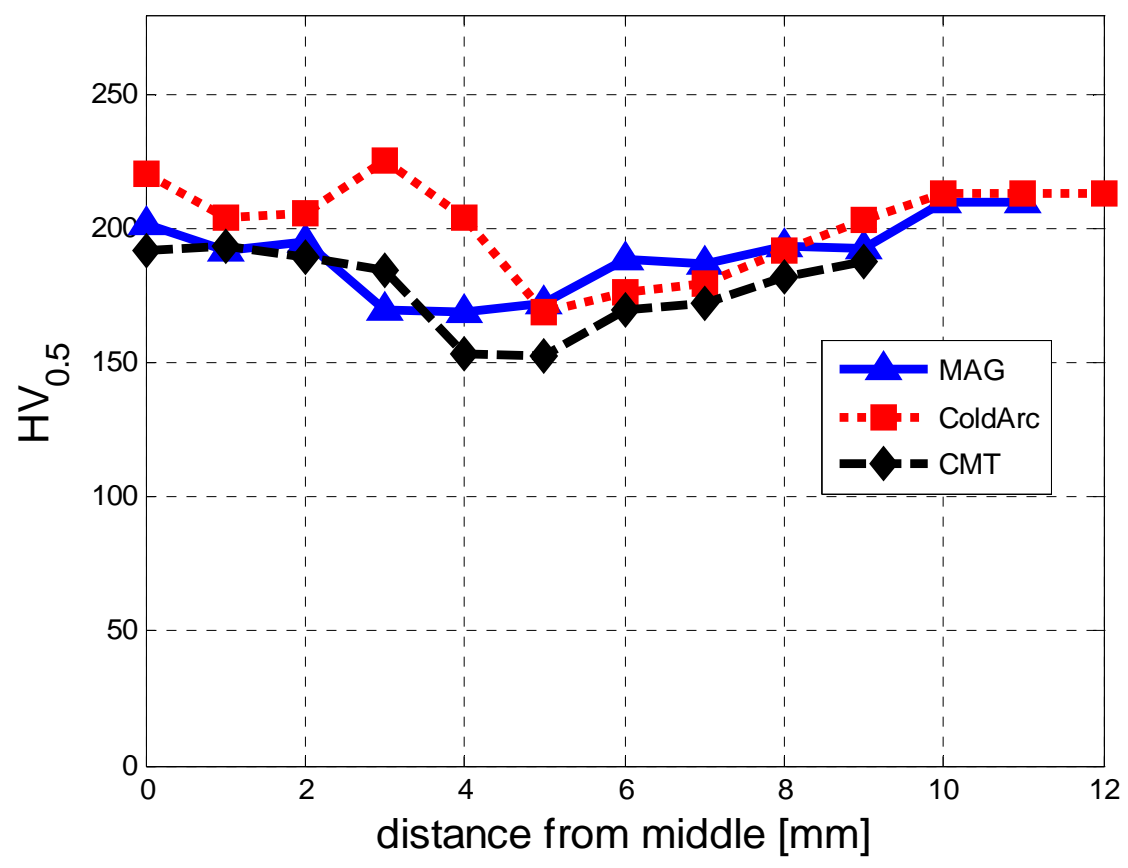

Fig. 10. Hardness profile in joints of DP800 steel for various welding methods

Hardness measurements demonstrated no essential effect of welding method on hardness distribution in the joint of DP800 steel grade. The highest hardness was found in the centre of weld (c. 200HV0.5). Within the heat-affected zone the hardness is decreasing to reach the minimum of c. $150 \mathrm{HV} 0.5$ at a distance of 4-6 mm from the weld centre depending on a given sample. Then, the hardness is rising to reach the value of $205 \mathrm{HV} 0.5$, i.e. the value of the parent metal.

\section{CONCLUSIONS}

The examinations having been carried out were to show advantages of low-energy methods with respect to classic MAG method with $100 \% \mathrm{CO} 2$ shielding. The following conclusions were drawn basing on the examinations:

- visual inspections have shown definitely better aesthetics of joints made with ColdArc and CMT methods featuring lack of spatters, regular shape of weld face and very low amount of oxides on the surface. 
- basing on strength tests, it was found that joint strength of HSLA340 and DC04 steel grades are very slightly dependent of the welding method. In all specimens of these grades the failure occurred beyond the joint area and the strength of joints was similar to that of the parent metal. It was only for the dual phase (martensitic/ferritic) steel, grade DP800, where the failure occurred in the heat-affected zone and the welding specimen strength was, on an average, $200 \mathrm{MPa}$ lower than that of the steel. It is also worth to mention that the strength of joints of this steel made with ColdArc and CMT methods is about $40 \mathrm{MPa}$ higher than that welded with classic short-circuit arc in $100 \%$ CO 2 shielding.

- no essential effect of the welding method on geometrical dimension of welds was found as a result of macroscopic examinations carried out. In case of CMT method, less face riser and no excess penetration bead was found on the weld root side.

- hardness measurements for welds of DP800 steel shown no essential differences in its distribution in plane parallel to the surface of sheet being joined together.

In the view of examinations having been carried out, it can be stated that low-energy methods applied for typical car-body steels do not directly translate into larger strength values of joints or the lower heat-affected zone. However, their unquestionable advantage is much higher aesthetics of joints which is not unimportant for the automotive industry.

\section{REFERENCES}

1. Grzybicki M., Jakubowski J., Comparative tests of welding of sheets made of car body steel using the CMT and MIG/MAG methods, Welding Technology Review, no. 10, 2009, in polish.

2. Kiszka A., Technological properties of low-energy welding methods ColdArc, CMT, AC Pulse and Cold Process, Welding Departments and Institutes symposium "Modern Applications of welding technology", Byczyna 2012, in polish

3. Matusiak J., Pfeifer T.,Low-energy arc welding methods in shield gases - the influence of material and technological conditions for quality of joints and pollution emissions to the environment, Institute of Welding Bulletin, 5 (2008), in polish

4. Jastrzębski A., Tasak E., Influence of pulsation of the MIG arc on the structure of aluminium alloys welds, Welding Technology Review, no. 7-8, 2009, in polish.

5. Klimpel A., Janicki D., Cyroń M., Pulse arc GTA automatic welding process of thin austenitic AISI 321 steel, Welding Technology Review, no. 2-3, 2006, in polish.

6. Bruckner J., The CMT - revolution of welding technology, Welding Technology Review, no. 23, 2006, in polish.

7. EWM Information brochure, Innovative welding processes MIG/MAG EWM, 2012.

8. Ignasiak A., Korzeniowski M., Ambroziak A., Investigation of microstructure of resistance spot-welded joints made of HSLA340 and DP600 Steel, Archives of Metallurgy and Materials, Vol. 57, Iss. 4/2012.

9. Senkara J., Contemporary car body steels for automotive industry and technological guidelines of their pressure welding, Welding Technology Review, no. 11, 2009, in polish.

10. Prodromos T., Mechanical properties of Dual-Phase steel, Research at the Institute For Materials Science and Mechanics of Materials of TU- Munich 2006. 
11. ThyssenKrupp Steel, Product information Deep-drawing steels, September 2008.

12. Multi-author work, Welding Handbook, Volume 1, American Welding Society 1998.

13. Multi-author work, ASM Handbook; Welding, Brazing and Soldering Volume 6, USA 1993. 